\title{
Green for hope and red for fear? Testing the color effect on the implicit achievement motive
}

\author{
Nicole Gruber ${ }^{1}$ \\ ${ }^{1}$ Department of Psychology, University of Regensburg, Regensburg, Germany.
}

Received 05.01.2018; Received revised 26.05.2018; Accepted 12.06.2018

Available online 30.06 .2018

\begin{abstract}
Specific colors unconsciously influence achievement-related behavior, but colors also affect the expression of specific hormones (like cortisol). As implicit motives are related to both behavior and hormones, the demonstration of implicit motives arousal by colors could build a bridge between these two phenomena. The goal of this study is to test how colors affect the two components of the implicit achievement motive hope of success (HS) and fear of failure (FF). Therefore, 61 healthy participants (44 female, $M_{\text {age }}=22.79, S D_{\text {age }}=3.95$ ) were tested with the TAT/PSE (Heckhausen, 1963) and randomly assigned to three experimental arousal situations (color red, green, blue) and one control group. Contrary to the expectations, there was no influence of green on HS and red on FF, but green and blue could reduce the implicit FF. The results indicate that colors could potentially interact with the implicit achievement motive and therefore should be taken into account for motive testing.
\end{abstract}

Keywords: Color, implicit motives, achievement motive, thematic apperception test, picture story exercise.

Address of correspondence: Nicole Gruber, Department of Psychology, Universität Regensburg, Universitätsstraße 31, D-93053 Regensburg, Germany.

E-mail: Nicole.Gruber@ur.de

\section{Introduction}

The effects of colors are important for various fields of psychology especially for advertising and applied psychology, but also for achievement-related behavior (Elliot \& Maier, 2014). The color red is associated with achievement avoidance behavior and negative cognitive performance (Elliot, Maier, Binser, Friedman, \& Pekrun, 2009; Smajic, Merritt, Banister \& Blinebry, 2014). For instance, people showed lower cognitive performance in an IQ-test just when the words are written on a red background (Maier, Elliot \& Lichtenfeld, 2008; Lichtenfeld, Maier, Elliot \& Pekrun, 2009) or they tended to choose easier tasks, when they are exposed to the color red instead of green or grey (Elliot et al., 2007). Therefore, the color red is associated with avoidance motivation. The reason behind this fact is that red from its evolutional meaning is associated with dominance and status, which depending on the context can be interpreted as a warning sign or a sign of attractiveness (Elliot, Maier, Moller, Friedman \& Meinhardt, 2007; Meier, D'agostino, Elliot, Maier \& Wilkowski, 2012). Mehta and Zhu (2009) found that red was related to avoidance motivation and achievement on a detailed-orientated task, whereas blue was associated with approach motivation and achievement on creative behavior. Similarly, there are positive effects of green on creative behavior (Lichtenfeld, Elliot, Maier, \& Pekrun, 2012). Also, neuropsychological research shows that red leads to greater right-hemispheric activation compared with green or gray (Elliot et al., 2007). Even though there are clear empirical results, this research is still criticized to be less theoretically based (Elliot \& Maier, 2014).

Research from medicine and photobiology indicates that colors are related to expressions of hormones, which also are important in the health context. The color red is related to the expression of cortisol and testosterone, and the color blue to salvia DHEAS and progesterone (Figueiro \& Rea, 2010; Sroykham \& Wongsawat, 2014). As green is negatively associated with inflammation and cortisol but positively with melatonin, it is used for phototherapy in newborn (Vecchi, Donzelli, Migliorini, \& Sbrana, 1983; Horne, Donlon \& Arendt 1991). Hormones are related to implicit motives. For example, the implicit achievement motive is closely related to the hormone argininevasopressin, the affiliation motive to oxytocin and the 
power motive to testosterone (McClelland, 1995; Schultheiss et al., 2010). Ball et al. (2014) also found that progesterone reduces the fear of failure in young cycling women. As the implicit achievement motive is related to achievement outcome (Brunstein, 2018), it could make sense to test how colors can arouse the implicit achievement motive.

The Thematic Apperception Test (TAT/PSE; Heckhausen, 1963; English language translation by Schultheiss, 2001) is a valid measurement instrument of the implicit achievement motive and its two components hope of success (HS) and fear of failure (FF). The test uses the technique of projection to get insights into the unconscious system of the participants. Therefore, people get presented six pictures with the instruction to invent stories about it by answering four specific questions. The rationale behind this procedure is that people project their own unconscious need onto the person in the picture, the so-called 'hero' of the story which is written down in the text. So afterward the stories are evaluated using a specific content coding system to assess the implicit motive (Heckhausen, 1963). These pictures are presented in black and white as colors could potentially affect motive arousal, even though the influence of colors on the specific picture stimuli was not yet assessed. Rutchick, Slepan, and Ferris (2010) already raised the idea that colors can affect implicit processes and therefore influence such projective measurements. They let people take a word completing-test and found that the color red leads to more failure and negative associations. Pravossoudovitch, Young, and Elliot (2014) reported, when testing with the implicit association test that the color red is unconsciously related to danger. Malone et al. (2013) also reported negative effects of red on the Rorschach test, another measurement for unconscious tendencies. Also, when recapitulating Elliot et al. (2007) assumptions of the way the red effect works - the "influence of red is posited to take place without individuals' awareness that avoidance motivation has been activated and is operative in the achievement context" (p. 156) - a potential relationship to the implicit fear of failure could be concluded.

Besides, the red effect is also depending on the context (Maier, Barchfeld, Elliot, \& Pekrun, 2009), therefore also cultural effects have an influence here (Elliot \& Maier, 2014). As from a stereotypical point of view in western culture, green is related to hope and red to fear in the achievement situation. Thus, this effect or the influence of colors on implicit motives has not yet been assessed with the TAT/PSE, even though colors show implicit influences here. In the Thematic Gestalt Test (TGT; Revers, Allesch \& Widauer, 1985), a modified version of the TAT, colored pictures are used as they should more likely arouse motives. Indeed, it could be attested that colored pictures lead to different scores than an achromatic TAT (Revers et al., 1985). Brackbill (1951) indicated that colored pictures lead to a more vivid form of projection, especially for clinical people. One central point of critics could be that the colors were chosen just by the authors, not previously tested and so less systematic. In this research, I want to test, how the specific colors red, green and blue influence the implicit achievement motive and its two components hope of success (HS) and fear of failure (FF). Furthermore, I want to assess how the attitude towards a color could affect the motive-arousal reaction, as this was mostly neglected in color-research. There are two opportunities: First, because the favorite-color is positively associated it could stimulate more motive specific arousal - or less motive arousal effects are visible because people are common with the color and habituated.

\section{Hypotheses}

According to the previously cited research, it is assumed that:

1. The color red should influence fear of failure scores, but not hope of success.

2. The color green should influence hope of success scores, but not fear of failure.

3. The color blue should influence hope of success scores, but not fear of failure.

Also, ones' own favorite color should not affect the effect of colors on motive arousal for hope of success or for fear of failure.

\section{Method}

\section{Participants}

To achieve a statistical power of .80 by a medium expected effect of $(f=.25)$ for the arousal condition, the sample size needed to be 48. Overall, 61 students (44 female) without color-deficit, age between 18 and 40 years $(M=22.79, S D=3.95)$ voluntary participated in the study; this is associated with a statistical power of .95. All were enrolled in different subjects (most teaching profession $N=$ 37 and business education $N=16$ ) from 1st to 9th semester $(M=4.83, S D=1.97)$. There was no reward except the feedback of the individual achievement motive. The experiment was approved according to the ethical standards; people thoroughly debriefed and had the opportunity to retract their data, even though no one retracted the data.

\section{Design and Materials}

The design was a $2 \times 4$ within between mixed design with the within factor (first half - second half) and the between factor (red, green, blue, control). The material was a computer version with the six pictures of Heckhausen TAT/PSE (Gruber, 2014) representing a smiling man at the desktop (picture A), a man in front of the director's office (picture B), two men at a workbench (picture C), teacher and student at the blackboard (picture D), a man working at the desk (E) and foreman and worker (F). The pictures $\mathrm{C}$ and $\mathrm{B}$ were used again in the post-test session as they are very valid to arouse the relevant motive components (Gruber, 2014), and to control how the color interacts with the same picture stimulus presented before, as color interacts with the situation (Maier et al., 2009). The picture order was the same for all participants as it is well evaluated in this form to prevent sequence-effects (Heckhausen, 1963). Therefore, also no incomplete counterbalancing of the pictures was done, what was also not possible as picture $\mathrm{C}$ and $\mathrm{B}$ had to stand at the end because they were previously used.

The colors were chosen according to the LCh model (Fairchild, 2005), where colors are defined by lightness, chroma, and hue. It was looked that they were equivalent regarding lightness and chroma (red LCh (58/60/22), green LCh $(58 / 60 / 156)$, blue LCh $(58 / 60 / 290))$. The colors were put in the TAT/PSE-pictures with a transparency gradient of $75 \%$, for the uncolored pictures an achromatic grey (LCh $(58 / 0 / 0))$ of same lightness was used. The transparency was chosen that the color can be perceived and interacts with the picture, but picture details are still 
visible to stimulate implicit achievement motive arousal (see Figure 1).

\section{Procedure}

Participants were randomly assigned to an url they have to use with the browser to start the test. First, they have to insert their demographic variables (individual code, age, gender, studying subject, and semester) and their favorite color (red, green, blue, other or none). After reading a standardized test-instruction according to Heckhausen (1963) and an addition of Lundy (1958) on the screen, they started the test. Each picture of the TAT/PSE (picture order for all participants: picture A, B, C, D - picture E, F, C, B) was presented for 20 seconds. Afterwards, the participants had to invent a story based on the seen picture within five minutes (one minute for each of the four questions: "1. What is going on? Who are the people? 2. What has led to this situation? What has happened before? 3. What are the people thinking about, feeling, or wanting? 4 . What will happen next? How will everything turn out?" (Schultheiss, 2001, p. 31), and another minute to complete and correct the answers). After four pictures finished, the next four pictures were presented in the specific color (red, green, blue and control). At the end of the test, the participants received an explanation of the TAT/PSE and had the opportunity to retract their data.

\section{Evaluation}

The inter-rater-agreement of the stories of two expert coders blind for the hypothesis was $r=.88$ for HS and $r=$ .86 for FF (tested on a random set of $10 \%$ of the stories). For testing general motive arousal two $2 \times 4$ ANOVA for repeated variables was calculated for testing time (HS1HS2; FF1-FF2) as depended variables and arousal situation (red, green, blue and control) as independent variables. Furthermore, to assess if one's own favorite color influences the arousal situation a $3 \times 2 \times 4$ ANOVA for repeated variables was calculated with favorite color as second between-factor in the analyses. For testing the color specific hypothesis separate $2 \times 2$ ANOVAs for color (color vs. control-group) and testing time were calculated. Finally, t-tests for within-groups and descriptive statistics were calculated to see the difference in the conditions. Furthermore, effect sizes are provided.

\section{Results}

First, people were asked for their favorite color: 10 reported red, 15 green and 19 blue, the rest did not have a specific favorite color or had another favorite color.

H1: There was no interaction effect of color $\mathrm{x}$ testing time for $\operatorname{HS}\left(F(1,28)=0.163, p=.689, \eta^{2} p=.006\right)$ and for $\mathrm{FF}\left(F(1,28)=0.092, p=.764, \eta^{2} p=.003\right)$. There were even no other statistical significant effects in the within-ttest comparison (see Table 1).

$H 2$ : There was no interaction effect of color $\mathrm{x}$ testing time for HS $\left(F(1,29)=1.330, p=.258, \eta^{2} p=.044\right)$ and also no interaction effect for fear of failure $(F(1,29)=$ $\left.1.106, p=.302, \eta^{2} p=.037\right)$. But as visible in figure 2 , there were significant effects in the within-group. When people were presented to green there was a significant decrease of fear of failure $\left(M_{T 1}=3.00, S D_{T 1}=2.28 ; M_{T 2}=\right.$ 1.37, $\left.S D_{T 2}=1.67, t(15)=2.403, p=.030, d=-.53\right)$. This was not visible in the control group $\left(M_{T 1}=3.40 ; S D_{T 1}=\right.$ $\left.1.68 ; M_{T 2}=2.80, S D_{T 2}=2.00, t(15)=0.854, p=.407\right)$.

H3: There was no interaction effect of color $\mathrm{x}$ testing time for HS $\left(F(1,28)=0.584, p=.451, \eta^{2} p=.020\right)$ and for FF $\left(F(1,28)=0.380, p=.543, \eta^{2} p=.013\right)$. But in the t-tests comparisons are visible: People had a significant decrease of fear of failure when they view the blue pictures $(M=2.00, S D=1.70)$ compared to the achromatic pictures in the first test $(M=3.13, S D=1.81 ; t(14)=2.241, p=$ $.042, d=-.56)$.
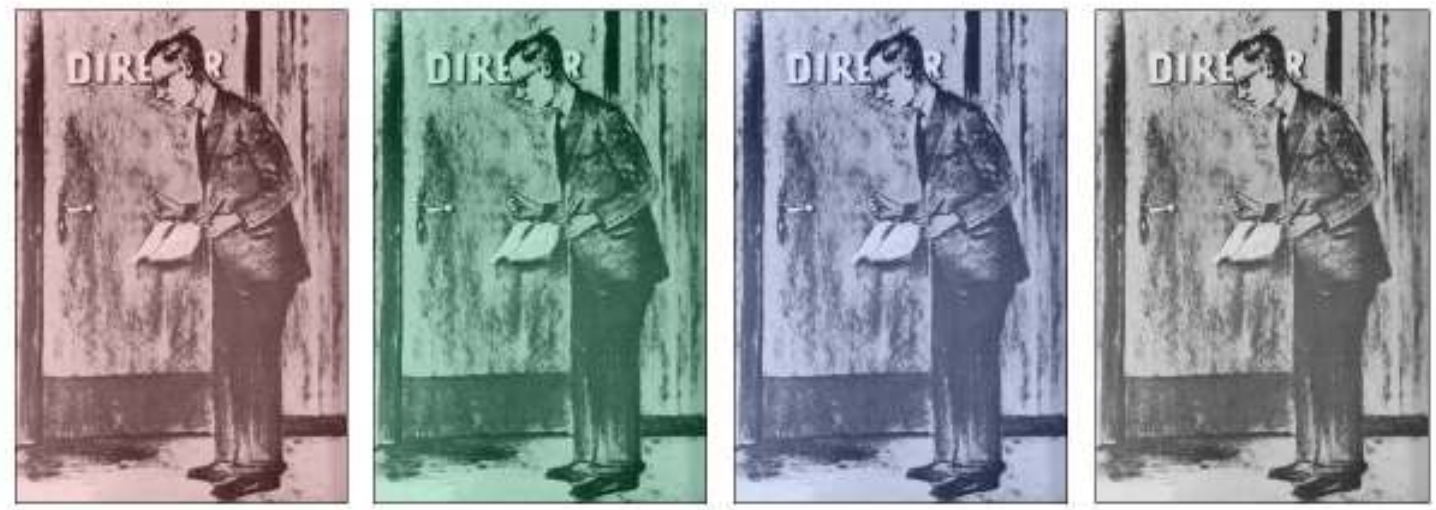

Figure 1. Scheme of color manipulation of the pictures 


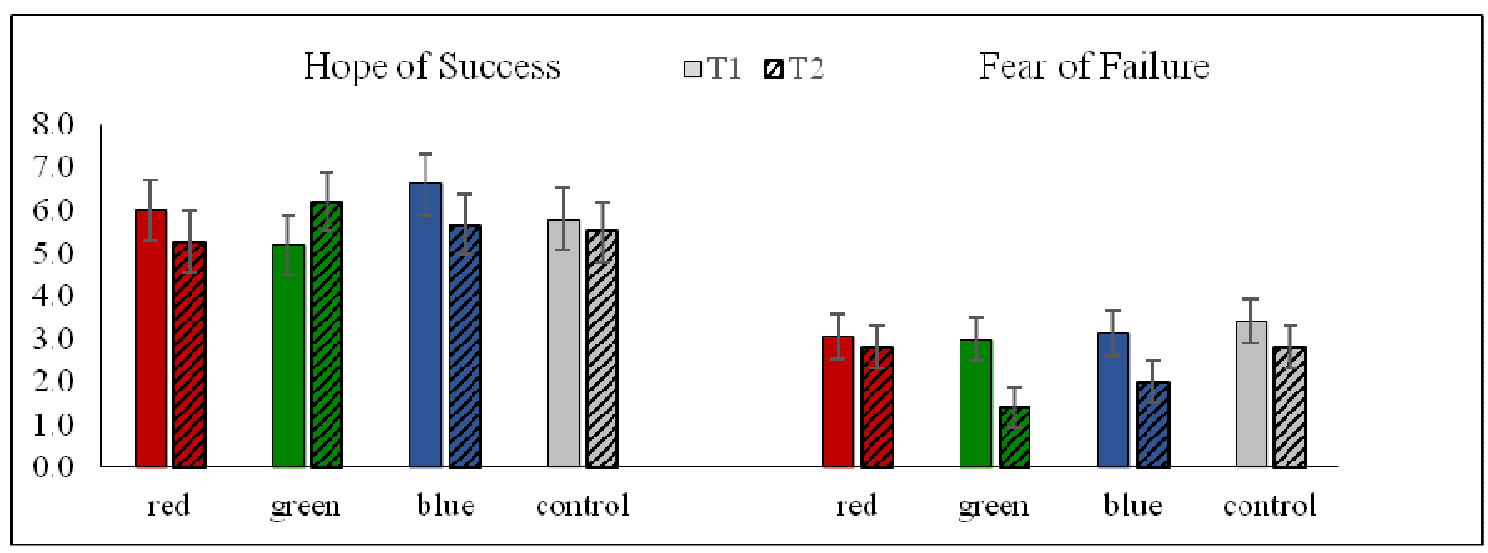

Figure 2. Overall scores of Hope of Success and Fear of Failure (error bars represent SEs)

Table 1. Means of motive scores (SDs in brackets) for Hope of Success (HS) and Fear of Failure (FF)

\begin{tabular}{lllllllllll}
\hline & $H S \_T 1$ & $H S \_T 2$ & $t$ & $p$ & $d$ & $F F \_T 1$ & $F F \_T 2$ & $t$ & $p$ & $d$ \\
\hline red & $6.00(3.29)$ & $5.27(2.28)$ & 0.735 & .474 & -.16 & $3.07(2.19)$ & $2.80(2.08)$ & 0.315 & .758 & -.08 \\
green & $5.19(2.25)$ & $6.18(2.76)$ & -1.095 & .291 & .31 & $3.00(2.28)$ & $1.37(1.67)$ & 2.403 & .030 & -.53 \\
blue & $6.60(3.46)$ & $5.67(3.75)$ & 1.434 & .173 & -.39 & $3.13(1.81)$ & $2.00(1.70)$ & 2.241 & .042 & -.56 \\
control & $5.80(1.82)$ & $5.53(1.64)$ & 0.459 & .653 & -.12 & $3.40(1.68)$ & $2.80(2.00)$ & 0.854 & .407 & -.24 \\
\hline
\end{tabular}

Regarding our last assumption, the analysis showed that there was no general interaction effect of color $\mathrm{x}$ testing time for hope of success $F(3,57)=1.183, p=.324$, $\eta^{2} p=.059$ nor fear of failure $F(3,57)=.753, p=.525, \eta^{2} p$ $=.038$. Furthermore, there was no general interaction effect of motive arousal and favorite color on hope of success $F$ $\left.(11,42)=.600, p=.817, \eta^{2} p=.136\right)$ but there was an effect for fear of failure $F(11,42)=2.042, p=.048, \eta^{2} p=$ $.348)$. The interaction indicated that the effects are stronger, when the color was not the favorite color. So for blue people, who have not the favorite color blue $\left(M_{T 1}=\right.$ $3.80 ; S D_{T 1}=2.30 ; M_{T 2}=1.87, S D_{T 2}=1.70, t(9)=2.355, p$ $=.043, d=.369)$ the effect was more visible than for people who reported that their favorite color is blue $\left(M_{T 1}=\right.$ $1.80, S D_{T 1}=.45, M_{T 2}=1.40 ; S D_{T 2}=1.67, t(4)=.492, p=$ $.648, d=-.57)$. The same effect was seen for the color green. Here people also had higher effects when their favorite color was not green $\left(M_{T 1}=3.07, S D_{T 1}=2.43, M_{T 2}\right.$ $\left.=1.28, S D_{T 2}=1.58, t(13)=2.381, p=.033, d=-.53\right)$ compared than when it was green $\left(M_{T 1}=2.50, S D_{T 1}=.70\right.$, $\left.M_{T 2}=2.00, S D_{T 2}=2.83, t=.333, p=.795, d=-.90\right)$.

\section{Discussion}

It was assumed that red would increase fear of failure (FF), as it is shown in previous research that red is implicitly related to danger and fear (Elliot et al., 2004; Rutchick et al., 2010; Pravossoudovitc et al., 2012; Malone et al., 2013) and also to an decrease of cognitive performance (Elliot et al., 2009). Both facts could be associated with an increase of FF, but it was not found that red presenting pictures in red leads to such an effect. Perhaps this could depend on the fact that also here a context $\mathrm{x}$ red-effect has occurred and for some people red was more linked to romance than with FF (Meier et al., 2012; Maier et al., 2009). Also, the assumption green would lead to an increase of hope of success (HS) because of a cultural stereotype, had to be declined - even though green was the only color where people reported a little increase of HS in the within-test. On the other hand, also the hypothesis that green does not influence FF had to be rejected because viewing the pictures colored in green leads to a decrease of FF in the within-group. So, green was not related to HS and red was not to FF.

Also blue had no influence on HS, but it showed fearreducing effects in the within-group comparison. This is interesting from the fact that normally the color blue increases the production of progesterone (Figueiro \& Rea, 2010; Sroykham \& Wongsawat, 2014). Also, an increase of progesterone is related to a decrease of FF (Ball et al., 2014), so there could be a potential connection between colors, hormones and implicit motives. The decrease of FF in the within-group by blue and green is interesting because these colors increase creative performance (Lichtenfeld et al., 2012; Mehta and Zhu, 2009) and FF is negatively related to creative behavior (Amabile \& Khaire, 2008). Covington (1985) found when people are more motivated by FF, they try to protect their self-worth and are less productive divergent thinking. Last, progesterone positively influences achievement in a creativity task (Bazanov et al., 2014). So from this point of argumentation, the reduced implicit fear of failure could explain other effects reported in applied psychology.

But at this stage, there are also open questions for new research. For example, if it matters how long people are exposed to specific colors and how intensive the color should be. As the colors potentially work differently (blue seems to reduce overall motive arousal, whereby green and red seem to work more specific), it could make sense to also include yellow in other studies. Also, further research in different cultural contexts and different age-groups are needed.

One's own favorite color does not affect the arousal effects for HS. But there were high influences of the 
favorite color on the arousal effect of the colors found on FF. Further investigation on this effect showed that the specific color (blue or green) reduced more fear of failure when it was not the favorite color. Perhaps people with favorite color are more exposed to the color and more habituated so that the specific reaction is less visible.

\section{Conclusions and Practical implications}

This study indicates (as also found by Rutchick et al. (2010) for projective word completing test, Pravossoudovitch et al. (2014) for the implicit association test and Malone et al. (2013) for the Rorschach test) that colors affect the implicit system and therefore should be taken into account when applying such tests. On the other hand, it gives more insights into the results of Revers et al. (1985) and Brackbill (1951). Colored TAT/PSE pictures do not only look more lifelike and therefore enhance motive arousal, but it is also possible that colors separately interact with specific components of the implicit achievement motive or implicit motives per se. To interpret the results from a practical view in applied work psychology, it can be interesting that blue and green can reduce fear of failure. So, that perhaps people with high FF-scores better work in environments where these colors are applied.

\section{References}

Amabile, T. A., \& Khaire, M. (2008). Creativity and the role of the leader. Harvard Business School Publishing.

Ball, A., Wolf, C. C., Ocklenburg, S., Brüne, M., Wolf, O. T., Güntürkün, O., \& Pinnow, M. (2014). The type of implicit motive enactment is modulated by sex hormones in naturally cycling women. Physiology \& Behavior, 123, 119-126. doi:10.1016/j.physbeh.2013.09.016

Bazanova, O. M., Kondratenko, A. V., Kuzminova, O. I., Muravlyova, K. B., \& Petrova, S. E. (2014). EEG alpha indices depending on the menstrual cycle phase and salivary progesterone level. Human Physiology, 2(40), 140-148.

Brackbill, G. A. (1951). Some effects of color in thematic fantasy. Journal of Consulting Psychology, 15(5), 412418.doi: 10.1037/h0055668

Brunstein, J.C. (2018). Implicit and explicit motives. In J. Heckhausen und H. Heckhausen. (Eds.), Motivation and Action (pp. 369-405). Berlin, Heidelberg: Springer.

Covington, M. V. (1985). Strategic thinking and the fear of failure. In J. W Segal, S. F. Chipman, \& R. Glaser (Eds.). Thinking and learning skills (pp. 389-416). New York: Routledge.

Elliot, A. J., Maier, M. A., Binser, M. J., Friedman, R., \& Pekrun, R. (2009). The effect of red on avoidance behavior in achievement contexts. Personality and Social Psychology Bulletin, 35, 365-375. doi: $10.1177 / 0146167208328330$

Elliot, A.J. \& Maier, M. A. (2014). Color psychology: effects of perceiving color on psychological functioning in humans. Annual Review of Psychology. 65, 95-120. doi: 10.1146/annurev-psych-010213-115035.

Elliot, A. J., Maier, M. A., Moller, A. C., Friedman, R., \& Meinhardt, J. (2007). Color and psychological functioning: the effect of red on performance attainment. Journal of Experimental Psychology: General, 136 (1), 154-168. doi: 10.1037/0096-3445.136.1.154

Fairchild, M. D. (2005). Color appearance models. New York, NY: John Wiley.

Figueiro, M.G. \& Rea, M.S. (2010). The effects of red and blue lights on circadian variations in cortisol, alpha amylase, and melatonin, International Journal of Endocrinology, 1-9. doi:10.1155/2010/829351
Gruber, N. (2014). Ist eine Computerversion bei der Messung impliziter Motive der Papier-Bleistift-Version überlegen? Einen Untersuchung am Beispiel des TAT nach Heckhausen [Is a computer-version superior to paperpencil-version in measuring implicit motives? An investigation using the TAT/PSE of Heckhausen]. Roderer: Regensburg. doi: 10.13140/2.1.1030.9923

Heckhausen, H. (1963). Hoffnung und Furcht in der Leistungsmotivation [Hope and fear components of achievement motivation] Meisenheim: Glain.

Holzmann, D.C. (2010). What's in a color? The unique human health effects of blue light. Environmental Health Perspective, 118 (1), 22-27. doi: 10.1289/ehp.118-a22

Horne, J. A., Donlon, J., \& Arendt, J. (1991). Green light attenuates melatonin output and sleepiness during sleep deprivation. Sleep, 14(3), 233-240. doi: doi.org/10.1093/sleep/14.3.233

Lichtenfeld, S., Elliot, A. J., Maier, M. A., \& Pekrun, R. (2012). Fertile green: Green facilitates creative performance. Personality and Social Psychology Bulletin, 38, 784-797. doi: 10.1177/0146167212436611

Lichtenfeld, S., Maier, M. A., Elliot, A. J., \& Pekrun, R. (2009). The semantic red effect: Processing the word red undermines intellectual performance. Journal of Experimental Social Psychology, 45, 1273-1276. doi: 10.1037/a0019689

Maier, M. A., Barchfeld, P., Elliot, A. J., \& Pekrun, R. (2009). Context-specificity of implicit preferences: The case of human preference for red. Emotion, 9, 734-738. doi: $10.1037 / \mathrm{a} 0016818$

Maier, M. A., Elliot, A. J., \& Lichtenfeld, S. (2008). Mediation of the negative effect of red on intellectual performance. Personality and Social Psychology Bulletin, 34(11), 1530-1540. doi: 10.1177/0146167208323104

Meier, B. P., D'agostino, P. R., Elliot, A. J., Maier, M. A., \& Wilkowski, B. M. (2012). Color in context: Psychological context moderates the influence of red on approach-and avoidance-motivated behavior. PloS one, 7(7), e40333.

Malone, J. C., Stein, M. B., Slavin-Mulford, J., Bello, I., Sinclair, S. J., \& Blais, M. A. (2013). Seeing red: Affect modulation and chromatic color responses on the Rorschach. Bulletin of the Menninger Clinic, 77(1), 70-93. doi: 10.1521/bumc.2013.77.1.70

McClelland, D.C. (1995). Achievement, motivation in relation to achievement-related recall, performance, and urineflow, a marker associated with release of vasopressin. Motivation and Emotion, 19, 59-76. doi: 10.1007/BF02260672

Mehta, R., \& Zhu, R. J. (2009). Blue or red? Exploring the effect of color on cognitive task performances. Science, 323(5918), 1226-1229. doi: 10.1126/science.1169144

Pravossoudovitch, K., Cury, F., Young, S. G., \& Elliot, A. J. (2014). Is red the colour of danger? Testing an implicit red-danger association. Ergonomics, 57(4), 503-510. doi: $10.1080 / 00140139.2014 .889220$

Revers, W.J., Allesch, C.G \&Widauer, H. (1985). Thematischer Gestaltungstest. Weinheim: Beltz.

Rutchick A. M., Slepian, M. L., Ferris, B. D. (2010). The pen is mightier than the word: object priming of evaluative standards. European Journal of Social Psychology, 40, 704-708. doi: 10.1002/ejsp.753

Schultheiss, O. C. (2001). Manual for the assessment of hope of success and fear of failure. English translation of Heckhausen's need achievement measures. Unpublished scoring manual. University of Michigan, Ann Arbor.

Schultheiss, O. C., Rösch, A. G., Rawolle, M., Kordik, A. \& Graham, S. (2010). Implicit motives: Current topics and future directions. In T. C. Urdan \& S. A. Karabenick (Eds.) The Decade Ahead: Theoretical Perspectives on Motivation and Achievement: Advances in motivation and 
achievement (Volume 16) (pp. 199-233). Bingley: Emerald.

Smajic, A., Merritt, S., Banister, C. \& Blinebry, A. (2014). The red effect, anxiety, and exam performance: A multidisciplinary examination. Teaching of Psychology, 41,37-43. doi : 10.1177/0098628313514176

Sroykham, W. \& Wongsawat, Y. (2014). The red and blue rooms affect to brain activity, cardiovascular activity, emotion and saliva hormone in women. Bmeicon (7), 1-4 doi: 10.1109/BMEICON.2014.7017432.

Vandewalle (2011). Spectral quality of light modulates emotional brain responses in humans. New York: Rockefeller University.
Vecchi, C., Donzelli, G. P., Migliorini, M. G., \& Sbrana, G. (1983). Green light in phototherapy. Pediatric Research, 17(6), 461-463. doi: 10.1203/00006450-198306000-00006

Viola, A.U., James, J.M., Schlangen, L.J., Dijk, D.J. (2008). Blue-enriched white light in the workplace improves selfreported alertness, performance and sleep quality. Scandinavian Journal of Work Environmental Health, 34(4), 297-306. doi:10.5271/sjweh. 